\title{
ANNOUNCEMENTS
}

NOTE: if the links below are inactive, this most likely means that you are using an outdated version of Adobe Acrobat Reader. Please update your Acrobat Reader at adobe.com and try the links again.

\section{CALLS FOR PAPERS}

1 Jun 2007 Deadline

1 Oct 2007 Deadline

30 Nov 2007 Deadline

Dec 2007 Deadline

\section{CONFERENCES}

2007, May
An International Symposium on Performance Science (ISPS) will convene at the Casa Da Música, Porto, Portugal, on 22-23 November 2007. Proposals (abstracts) for unpublished papers and posters "on research that explores the interface between skilled artistry and scientific discovery" are welcome; the deadline for submittal is 1 June 2007. Additional information may be obtained by visiting the conference web site at www.isps.rcm.ac.uk and clicking the "call for papers" link.

A two-day international conference, the Empirical Musicology Institute of Musical Research, will be held at the University of London on 2-3 April, 2008. Contributions are welcome from researchers at all levels and are especially encouraged from postgraduate students and researchers early in their careers. Abstracts for papers (200 words) and posters (100 words) may be sent to the Administrator, Institute of Musical Research (music@sas.ac.uk). Additional information is available at http://www.sempre.org.uk/conf details.html?id=33

The $4^{\text {th }}$ Conference on Interdisciplinary Musicology (CIM'08) will be held in Thessaloniki, Greece on July 2-6, 2008. Information on the conference is available at http://www-gewi.uni-graz.at/staff/parncutt/cim.htm; a "Call for Papers" PDF file may be downloaded from that web page.

The $10^{\text {th }}$ International Conference on Music Perception and Cognition (ICMPC10) will be held at the Center for Research and Development in Higher Education at Hokkaido University in Sapporo, Japan on August 25-28, 2008. The expected deadline for submission of proposals will be in December 2007 (exact date not yet available). The organizers have set up a conference blogsite at http://icmpc10.typepad.jp/.

A conference on Language and Music as Cognitive Systems will be held May 11-13, 2007 at the University of Cambridge, UK. The event is structured around four core areas in which the collaboration between music and language has proven to be particularly fruitful: (1) Structural comparisons between language and music; (2) Evolution of language and music; (3) Learning and processing of language and music; and (4) Neuroscience of language and music. Keynote speakers will include Ray Jackendoff (Tufts University), Tecumseh Fitch (University of St. Andrews), Jamshed Bharucha (Tufts University), and Aniruddh Patel (The Neurosciences Institute, San Diego). Additional information is available on the conference home page, http://www.crassh.cam.ac.uk/events/2006-7/language-music.html 
2007, May

2007, June

2007, July-August

2007, August

2007, September

2007, September

2007, November

2008, April
The $\mathbf{3}^{\text {rd }}$ International Symposium on Cognition and Musical Arts will be held in Salvador, Bahia, Brazil from May 21 through May 25, 2007. Salvador is a touristic city in Northeast Brazil, known for its beauty, regional food, and music. Keynote speakers will be Drs. Aaron Williamon (Royal College of Music) and Daniel Levitin (McGill University). Information on the conference is available at http://www.simcam.ufba.br/ .

The $6^{\text {th }}$ Creativity and Cognition Conference will be held June 13-15, 2007 in Washington, DC, USA. Proposals are welcomed from "researchers, developers, artists, practitioners, and policy-makers, including: computer and information scientists; diverse scientists, engineers, and architects; product, graphic, and interaction designers; writers, musicians, and digital artists; creative practitioners, corporate leaders, and educators; social scientists, ethnographers, and anthropologists." Full information on the conference may be obtained at http://www.cs.umd.edu/hcil/CC2007/

SMPC 2007, the biennial meeting of the Society for Music Perception and Cognition, will take place at Concordia University (Montreal, Quebec, Canada) from July 30 to August 3, 2007. The early registration deadline has been reset to May 20, 2007. Paper and poster proposals in the areas of music theory, psychology, psychophysics, linguistics, neurology, neurophysiology, ethology, ethnomusicology, artificial intelligence, computer technology, physics, and engineering will be offered. Additional information may be found at http://alcor.concordia.ca/ smpc2007/

The $3^{\text {rd }}$ Conference on Interdisciplinary Musicology (CIM07) will take place in Tallinn, Estonia from 15 to 19 August 2007. The theme of CIM07 is singing from the viewpoint of all musically and musicologically relevant disciplines. Visit the conference web site at http://www-gewi.uni-graz.at/cim07/index2.htm for further information.

The 8th International Conference on Music Information Retrieval (ISMIR 2007) will be held at the Vienna University of Technology in Vienna, Austria, from Sunday, September 23 to Thursday, September 27, 2007. The overall goal of this annual conference series is to provide a forum for those involved in accessing digital musical material, and topic areas of the conference include "Music Perception, Cognition, Affect, Emotions" and "Human-Computer Interaction and Interfaces." Additional information is available at http://ismir2007.ismir.net/cfp.html

Music-AL Workshop 2007, organized by the Interdisciplinary Centre for Computer Music Research, will convene on September 10, 2007 at the Belem Cultural Centre, in Lisbon, Portugal. Additional information is available at http://cmr.soc.plymouth.ac.uk/Musical2007/

International Symposium on Performance Science (ISPS), Porto, Portugal (see CALLS FOR PAPERS, above)..

Empirical Musicology Institute of Musical Research, University of London (see CALLS FOR PAPERS, above). 
2008, July

2008, August
The $4^{\text {th }}$ Conference on Interdisciplinary Musicology (CIM'08), Thessaloniki, Greece (see CALLS FOR PAPERS, above).

$10^{\text {th }}$ International Conference on Music Perception and Cognition (ICMPC10), Hokkaido University, Sapporo, Japan (see CALLS FOR PAPERS, above).

Empirical Musicology Review welcomes announcements of national and international symposia, conferences, workshops, and other activities advancing empirical research in music. Please send announcements to editor@emusicology.org . 